\title{
Eye Symptoms with Short-term PAP Therapy
}

Timo Elomaa

Lääketieteen kandidaatti

Helsingin yliopistollinen sairaala, sydän- ja keuhkokeskus, uniyksikkö

Helsinki 11.10.2018

Tutkielma

timo.elomaa@helsinki.fi

Ohjaaja: Adel Bachour

HELSINGIN YLIOPISTO

Lääketieteellinen tiedekunta 


\section{Eye Symptoms with Short-term PAP Therapy}

Elomaa et al., J Sleep Disor: Treat Care 2017, 6:3

DOI: $10.4172 / 2325-9639.1000204$

Timo Elomaa ${ }^{1}$, Marita Uusitalo ${ }^{2}$, Paula Maasilta ${ }^{1}$, Adel Bachour $^{1}$

1- Sleep Unit, Pulmonary Department, Heart and Lung Center, Helsinki University Hospital and Helsinki University, Finland.

2- Department of Ophthalmology, Helsinki University Hospital and Helsinki University, Finland.

Correspondence: Timo Elomaa

University of Helsinki, faculty of medicine

Address: Helsinki University Hospital, Heart and lung center, sleep unit Meilahdentie 2, PL 160, 00029 HUS, FINLAND

Email: timo.elomaa@helsinki.fi

\section{Introduction}

Obstructive sleep apnea (OSA) is a disorder characterized by short apneas or hypopneas during sleep. These pauses in breathing lead to disruption of sleep and hypoxemia. The diagnosis could be done by polysomnography or by a home sleep apnea study at home [1]. If untreated, sleep apnea may aggravate or even cause a variety of diseases, such as cardiovascular and metabolic diseases $[2,3]$. The current treatment for sleep apnea, along with lifestyle counseling, is positive airway pressure (PAP) treatment. PAP uses positive pressure to assist the patient's own breathing and helps keep the airway open during sleep $[3,4]$ 
PAP treatment is administered via a mask that is worn while sleeping [5]. The treatment is generally not well tolerated, mainly due to discomfort [6].

There are few studies regarding eye symptoms with PAP therapy. Hayirci et al showed an increase in Nelson classification of squamous metaplasia score and in Schirmer 1 score in the right eye with short-term PAP therapy [7]. A case study by Harrison et al showed three patients that experienced dryness and irritation of the eyes after PAP initiation [8]. Conversely, Kadyan et al [9] showed that in obstructive sleep apnea patients the continuous use of PAP diminishes ocular symptoms and improves tear film compared to non-users, mainly due to better sleeping habits and posture. Acar et al [10] showed similar findings with long-term use. There are also sporadic reports of eye symptoms caused by air regurgitation through the nasolacrimal system with PAP use [11-13].

In this pilot study, we evaluated eye symptoms before PAP initiation, a few days after PAP initiation and at 2-3 months of PAP therapy. We were interested in determining if there was any change in eye symptoms during PAP therapy.

\section{Methods}

Sleep apnea patients referred to our Sleep Unit for PAP initiation were asked to complete a questionnaire about their eye symptoms at baseline, 3-5 days after initiation and at 2-3 months of PAP therapy. Our unit is a tertiary referral centre for obstructive sleep apnea. For each patient, our sleep nurses carefully selected the most suitable mask interface and checked for a possible disturbing leak before starting PAP therapy. Furthermore our nurses observed the patients' facial shapes and verified the direction of the intentional air leak emerging from the vent before choosing the best suitable mask.

The questionnaire consisted of four questions:

Question 1: Have you had any eyelid or lacrimal surgery? Yes/no, if yes then specify. 
Question 2: Do you have any dry eye symptoms? i.e. you have a foreign body sensation or your eyes are easily irritable and become red (for example in windy weather).

The patient placed a mark over a Visual Analog Scale (VAS) ranging from 0 (symptom free) to 100 (severe symptoms).

Dry eye symptom values were derived from this question.

Question 3: Do you have eye watering while indoors?

This question was also scored on a VAS ranging from 0 (no watering) to 100 (severe watering). This question was asked separately for the right and the left eye.

Left and right watering values were derived from this question.

Question 4: Do you use artificial tears? Yes/no, if yes, then please indicate the brand and the dose.

Patient characteristics and PAP data:

Data from the patient file about comorbidities, allergies, medications, BMI and age was collected. Additional data was obtained from the ResScan program regarding the following PAP parameters: apnea and hypopnea index (AHI), oxygen desaturation index of $3 \%$ (ODI3), mask leak, mask type, mask brand, daily PAP use, pressure, pulse and $\mathrm{SpO}_{2}$.

A patient was considered PAP adherent if the use of PAP therapy was 4 hours or more per day. Conversely, a patient was considered non-adherent if the use was under 4 hours.

We used the age-adjusted Charlson comorbidity index (CCI) to evaluate comorbidity. This index encompasses 19 medical conditions weighted from 1 to 6 with total scores ranging from 0 to 37 ( $0=$ no comorbidity) [14].

The study was approved by the Helsinki University Hospital authorization committee (code 4/2016, date 15.8.2016). 


\section{Statistics}

Results were generated using a computerized statistical package (IBM SPSS® Statistics 21.0, Armonk, NY, USA). Data was checked for normality using Shapiro-Wilk methods. All p-values were two-sided, and the significance level was set at 0.05 throughout. Eye symptoms at baseline and with PAP were compared using paired t-test when applicable. ANOVA and Chi test were used when appropriate. We also used the bivariate Pearson correlation.

\section{Results}

We included 46 patients (14 women). Mean age \pm SD was $56.0 \pm 15.9$, mean BMI 31.7 \pm 6.0 , mean AHI $34.1 \pm 21.8$, mean ODI3 $34.4 \pm 20.7$, mean oxygen saturation $91.6 \pm$ 2.9, mean nadir $\mathrm{SpO}_{2} 79.1 \pm 8.2 \%$, mean CT90\% (cumulative time with $\mathrm{SpO} 2$ under 90\%) $20.9 \pm 26.8$ and mean CCI $1.8 \pm 2.3$ (Table 1). Out of the 46 participants, 45 answered the questionnaire at baseline, 39 at four days and 24 at two months.

\section{Dry eye symptom values}

The mean \pm SD dry eye symptom values at baseline were $27.5 \pm 26.6$, at four days of PAP therapy $28.7 \pm 26.0$ and at two months $30.0 \pm 28.2$. We did not find a significant difference between these groups $[\mathrm{F}(2,108)=0.071 ;(\mathrm{p}=0.932)]$ (Figure 1).

Seven patients regularly used artificial tears. Despite artificial tear therapy, the dry eye symptom values at baseline in these patients were slightly higher than the rest of the group, but did not reach a statistically significant difference (34.4 \pm 16.4 vs. $26.3 \pm 28.0$, respectively, $[\mathrm{F}(1,44)=0.553 ;(\mathrm{p}=0.461)]$.

Eight patients reported using medications that may cause dry eye symptoms. None of these patients discontinued PAP therapy during this study. Moreover, their dry eye symptom values did not differ significantly from the rest of the study group $(28.4 \pm 30.4$ vs. $27.4 \pm 26.1$, respectively $[\mathrm{F}(1,44)=0.010 ;(\mathrm{p}=0.923)]$.

Four patients reported previous eyelid surgery; eye symptoms in these patients did not differ from the rest of the study population. 


\section{Watering values}

No significant difference in the watering value for the right eye was found between baseline $(17.7 \pm 22.0)$, at four days $(15.6 \pm 21.3)$ or at two months $(21.0 \pm 26.4)[\mathrm{F}(2$, $108)=0.408 ;(\mathrm{p}=0.666)]$. The left eye showed similar results: $16.9 \pm 20.7$ (baseline), $16.3 \pm 21.7$ (four days) and $21.3 \pm 25.5$ (two months) $[\mathrm{F}(2,108)=0.418 ;(\mathrm{p}=0.659)]$ (Figure 2).

\section{Mask air leak}

We tested if there was any correlation between the severity of eye symptoms and PAP mask leaking. We found a statistically significant correlation between the severity of the $95^{\text {th }}$ percentile mask leak and the watering values in the left or right eye at two months of PAP therapy (Pearson correlation $r=0.393, n=48, p=0.006$ ) (Figure 3). No correlation was found regarding dry eye symptom values and air leak.

\section{Mask type and brand}

Six patients initially used nasal pillow masks, 34 patients used nasal masks and for six patients a full face mask was chosen. Four patients had F\&P masks and the rest had Resmed masks. All patients had an additional humidifier. For two patients, we switched their nasal mask to a full face mask to reduce mouth air leak. We did not find any significant difference in eye symptoms related to the type or the brand of the mask at baseline, at four days or two months of PAP use. We also did not find any difference in the $95^{\text {th }}$ percentile of mask leak between mask types.

\section{PAP adherence}

Non-adherent PAP patients had significantly higher dry eye symptom values at baseline $(37.6 \pm 30.6)$ than the adherent patients $(18.8 \pm 19.0)[\mathrm{F}(1,44)=6.307 ;(\mathrm{p}=0.016)]$ This difference became more prominent at two months of PAP therapy: $50.4 \pm 27.2$ (nonadherent) vs. $15.5 \pm 18.8$ (adherent) $[\mathrm{F}(1,23)=13.929 ;(\mathrm{p}=0.001)]$. 
We also found a similar difference in the watering values at two months of PAP therapy in these groups: $32.6 \pm 27.3$ (non-adherent) vs. $12.9 \pm 21.3$ (adherent) $[\mathrm{F}(1,47)=7.874$; $(\mathrm{p}=0.007)]$.

\section{Discontinuing vs. continuing PAP}

Five patients discontinued PAP therapy during the study. The mean dry eye symptom and watering values at baseline and the $95^{\text {th }}$ percentile air leak values in these patients did not differ from the rest of the subjects.

\section{Discussion}

In this pilot study, we found no significant change in the patient eye symptoms with shortterm PAP therapy.

Hayirci et al [7] have reported an increase in ocular irritation, tear evaporation and squamous metaplasia in the conjunctiva of the patients' right and left eyes with short-term CPAP therapy. The authors suggested that their observations may be due to a contact between the mask and the ocular surface, or dislocation or misplacement (or both) of the PAP mask leading to air leak. We believe that air leak from the mask directed to the eyes, intentional or unintentional, may play a major role in exacerbating or causing eye symptoms. In this study, we observed some correlation between mask leak and severity of eye watering.

We found no significant differences in eye symptoms related to the type of PAP mask used. We have previously reported that a disturbing air leak is not correlated to the amount of measured leak [15]. Leaks directed to the eye area may induce eye symptoms during PAP therapy. To avoid this problem, our sleep nurses carefully selected the most suitable mask interface for each patient and checked for a possible disturbing leak before starting PAP therapy. The nurses took in consideration the direction of the intentional air leak emerging from the vent and the patients' facial shapes. We believe that these precautions could in part explain the absence of change in eye symptoms during this study and also the absence of differences in mask leak between those who discontinued PAP therapy and those who continued PAP therapy. 
Our results agree with the findings of Kadyan et al. [9]. The authors reported amelioration in ocular symptoms and improvement in tear film with continuous PAP therapy compared to no therapy. They explained that these changes were due to better sleeping habits and sleeping posture. We do not have an explanation for this finding, meanwhile we noticed that our adherent PAP patients had significantly lower dry eye symptom values than the other patients.

Seven of our patients regularly used artificial tears, indicating the existence of dry eye disease in $15 \%$ of our studied sleep apnea patients referred for PAP therapy. We found no comparison values for this reported percentage in the literature. In the general population, the prevalence of dry eye disease varies between 5 and 35\% [16-18]. The real prevalence of dry eye disease among sleep apnea patients is unknown. Nevertheless, Hsiao et al., [19] have studied subjects without sleep apnea but suffering from sleep disorders. These researchers reported a higher prevalence of Sjögren syndrome in the subjects with sleep disorders than in those without. We believe that sleep apnea patients suffer more often from dry eye disease than the general population. This possibility needs to be confirmed in the future.

\section{Limitations of the study}

Our study has some limitations. As this is a pilot study, no statistical power calculations were done. Our follow-up time was relatively short (two months). We have previously reported cases of eye symptoms evolving years after PAP initiation [11]. We did not measure eye symptoms objectively, an ophthalmologist did not examine the patients and we did not explore the presence of floppy eyelid syndrome, as this syndrome is usually associated with sleep apnea and constitutes as a common cause of ocular irritation [20, 21].

\section{Future perspectives}

Future studies should include a larger number of patients for a longer period of time. Objective testing for dry eye disease should also be performed. 


\section{Conclusions}

When assuring good individual PAP mask interface adjustment, short-term PAP therapy did not increase eye symptoms in sleep apnea patients. An initial PAP preparation is therefore essential in preventing the emergence of eye symptoms.

\section{Acknowledgements}

We would like to thank our sleep nurse Joni and the head nurse Doris Bärenson for their assistance.

This study was done as a part of a dissertation medical work of the first author at the University of Helsinki, Faculty of Medicine.

This research did not receive any specific grant from funding agencies in the public, commercial, or not-for-profit sectors. We have no affiliation with ResMed or with F\&P companies. Our PAP devices and interfaces were selected according to local Finnish regulation.

\section{Funding}

No funding was received for this research.

\section{Conflict of Interest}

All authors certify that they have no affiliations with or involvement in any organization or entity with any financial interest (such as honoraria; educational grants; participation in speakers' bureaus; membership, employment, consultancies, stock ownership, or other equity interest; and expert testimony or patent-licensing arrangements), or non-financial interest (such as personal or professional relationships, affiliations, knowledge or beliefs) in the subject matter or materials discussed in this manuscript. 


\section{Ethical approval}

All procedures performed in studies involving human participants were in accordance with the ethical standards of the institutional and/or national research committee and with the 1964 Helsinki declaration and its later amendments or comparable ethical standards.

\section{Informed consent}

Informed consent was obtained from all individual participants included in the study.

\section{References}

1. Bachour A, Aalto T and Maasilta P (2016) Home Sleep Apnea Study of Patients with Limited to No Mobility. J Sleep Disor: Treat Care, S1. http://dx.doi.org/10.4172/2325-9639.S1-001

2. Guilleminault C Abad VC. Obstructive sleep apnea syndromes (2004). Med Clin North Am. 88:611-30.

3. Saaresranta T, Polo O. Uniapnea. In: Kaarteenaho R, Brander P, Halme M, Kinnula V. Keuhkosairaudet - Diagnostiikka ja hoito, Helsinki: (2013) Duodecim publishing.

4. Giles TL, Lasserson TJ, Smith BH, White J, Wright J, Cates CJ. (2006) Continuous positive airway pressure for obstructive sleep apnoea in adults. Cochrane Database Syst Rev. 3:CD001106.

5. Andrade RG, Piccin VS, Nascimento JA, Viana FM, Genta PR, Lorenzi-Filho G. (2014) Impact of the type of mask on the effectiveness of and adherence to continuous positive airway pressure treatment for obstructive sleep apnea. J Bras Pneumol. 40:658-68.

6. Weaver TE, Grunstein RR. (2008) Adherence to continuous positive airway pressure therapy: the challenge to effective treatment. Proc Am Thorac Soc. $5: 173-8$. 
7. Hayirci E, Yagci A, Palamar M, Basoglu OK, Veral A. (2012) The effect of continuous positive airway pressure treatment for obstructive sleep apnea syndrome on the ocular surface. Cornea. 31:604-8.

8. Harrison W, Pence N, Kovacich S. (2007) Anterior segment complications secondary to continuous positive airway pressure machine treatment in patients with obstructive sleep apnea. Optometry. 78:352-5.

9. Kadyan A, Asghar J, Dowson L, Sandramouli S. (2010) Ocular findings in sleep apnoea patients using continuous positive airway pressure. Eye (Lond). 24:84350.

10. Acar M, Firat H, Yuceege M, Ardic S. (2014) Long-term effects of PAP on ocular surface in obstructive sleep apnea syndrome. Can J Ophthalmol. 49:217-21.

11. Bachour A, Maasilta P, Wares J, Uusitalo M (2017) Bubbling test to recognize retrograde air escape via the nasolacrimal system during positive airway pressure therapy. Sleep Med. 29:35-36. doi: 10.1016/j.sleep.2016.08.026.

12. Singh NP, Walker RJ, Cowan F, Davidson AC, Roberts DN. (2014) Retrograde air escape via the nasolacrimal system: a previously unrecognized complication of continuous positive airway pressure in the management of obstructive sleep apnea. Ann Otol Rhinol Laryngol.123:321-4.

13. Vicinanzo MG, Allamneni C, Compton CJ, Long JA, Nabavi CB. (2015) The Prevalence of Air Regurgitation and Its Consequences After Conjunctivodacryocystorhinostomy and Dacryocystorhinostomy in Continuous Positive Airway Pressure Patients. Ophthal Plast Reconstr Surg. 31:269-71.

14. William H Hall, Ramanathan Ramachandran, Samir Narayan, Ashesh B Jani, Srinivasan Vijayakumar. (2004) An electronic application for rapidly calculating Charlson comorbidity score. BMC Cancer. 4:94.

15. Bachour A, Vitikainen P, Virkkula P, Maasilta P. (2013) CPAP interface: satisfaction and side effects. Sleep Breath. 17:667-72. doi: 10.1007/s11325-0120740-0.

16. DEWS (2007). The epidemiology of dry eye disease: report of the Epidemiology Subcommittee of the International Dry Eye WorkShop Ocul Surf. 5:93-107.

17. Schaumberg DA, Dana R, Buring JE, Sullivan DA. (2009) Prevalence of dry eye disease among US men: estimates from the Physicians' Health Studies. Arch Ophthalmol. 127(6):763-8. 
18. Schaumberg DA, Sullivan DA, Buring JE, Dana MR. (2003) Prevalence of dry eye syndrome among US women. Am J Ophthalmol. 136:318-26.

19. Hsiao YH, Chen YT, Tseng CM, Wu LA, Lin WC, Su VY, Perng DW, Chang SC, Chen YM, Chen TJ, Lee YC, Chou KT. (2015) Sleep disorders and increased risk of autoimmune diseases in individuals without sleep apnea. Sleep. 38:581-6.

20. Leibovitch I, Selva D. (2006) Floppy eyelid syndrome: clinical features and the association with obstructive sleep apnea. Sleep Med. 7:117-122.

21. Rossiter JD, Ellingham R, Hakin KN, et al. (2002) Corneal melt and perforation secondary to floppy eyelid syndrome in the presence of rheumatoid arthritis. $\mathrm{Br} \mathrm{J}$ Ophthalmol. 86:483. 
Table 1: Characteristics of the study population and PAP therapy details

\begin{tabular}{|c|c|c|c|}
\hline & $\begin{array}{l}\text { Number of } \\
\text { subjects }\end{array}$ & Mean & $\begin{array}{l}\text { Standard } \\
\text { Deviation }\end{array}$ \\
\hline Age, years & 46 & 56.0 & 15.9 \\
\hline BMI, $\mathrm{kg} / \mathrm{m}^{2}$ & 46 & 31.7 & 6.0 \\
\hline CCI & 46 & 1.8 & 2.3 \\
\hline $\mathrm{AHI} / \mathrm{h}$ & 46 & 34.1 & 21.8 \\
\hline ODI3/h & 45 & 34.4 & 20.7 \\
\hline $\mathrm{SPO}_{2}$ mean & 46 & 91.6 & 2.9 \\
\hline nadir $\mathrm{SPO}_{2}$ & 44 & 79.1 & 8.2 \\
\hline СТ90\% & 36 & 20.9 & 26.8 \\
\hline $\begin{array}{l}\text { PAP median pressure, } \mathrm{cm} \\
\mathrm{H}_{2} \mathrm{O}\end{array}$ & 45 & 7.9 & 2.4 \\
\hline $\begin{array}{l}\text { Unintentional leak, median, } \\
\mathrm{L} / \mathrm{min}\end{array}$ & 46 & 4.9 & 7.4 \\
\hline $\begin{array}{l}\text { Unintentional leak, } 95^{\text {th }} \% \text {, } \\
\mathrm{L} / \mathrm{min}\end{array}$ & 46 & 19.4 & 13.2 \\
\hline $\begin{array}{l}\text { Average PAP usage/day, } \\
\text { h:min }\end{array}$ & 46 & 4:09 & $2: 16$ \\
\hline $\begin{array}{l}\text { Median PAP usage/day, } \\
\text { h:min }\end{array}$ & 46 & $5: 11$ & $2: 15$ \\
\hline
\end{tabular}

Abbreviations: $\mathrm{BMI}=$ body mass index; $\mathrm{CCI}=$ age-adjusted Charlson comorbidity index; $\mathrm{AHI}=$ apnea and hypopnea index; ODI3 = Oxygen desaturation index of 3\%; CT90\% = Cumulative time with $\mathrm{SpO}_{2}$ under 90\%; Average PAP use $=$ total hours used $/$ total days; Median PAP use $=$ total hours used/PAP used days 
Eye dryness symptoms in PAP users

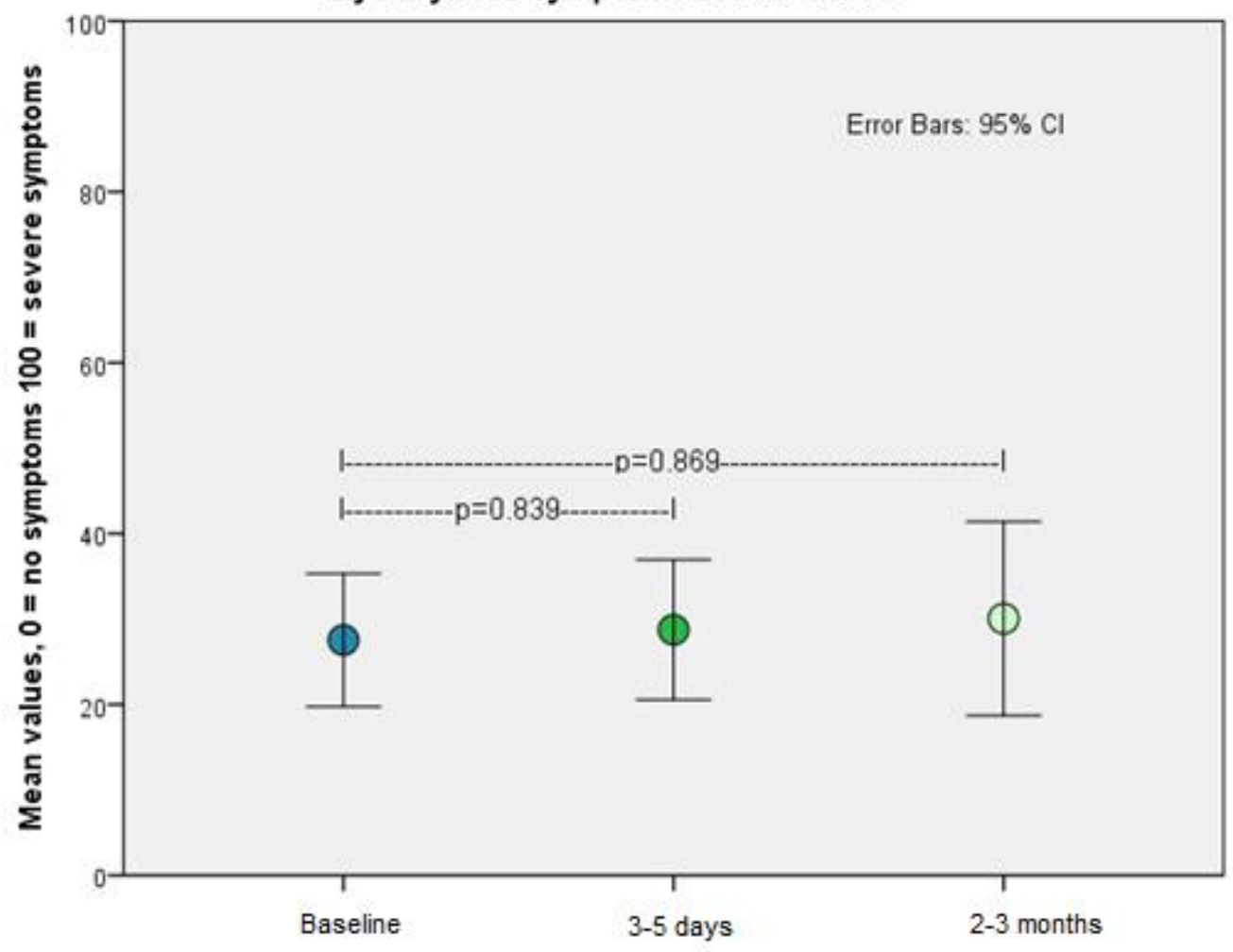

Figure 1: Dry eye symptom values with PAP therapy at four days and two months. No significant difference was found. 


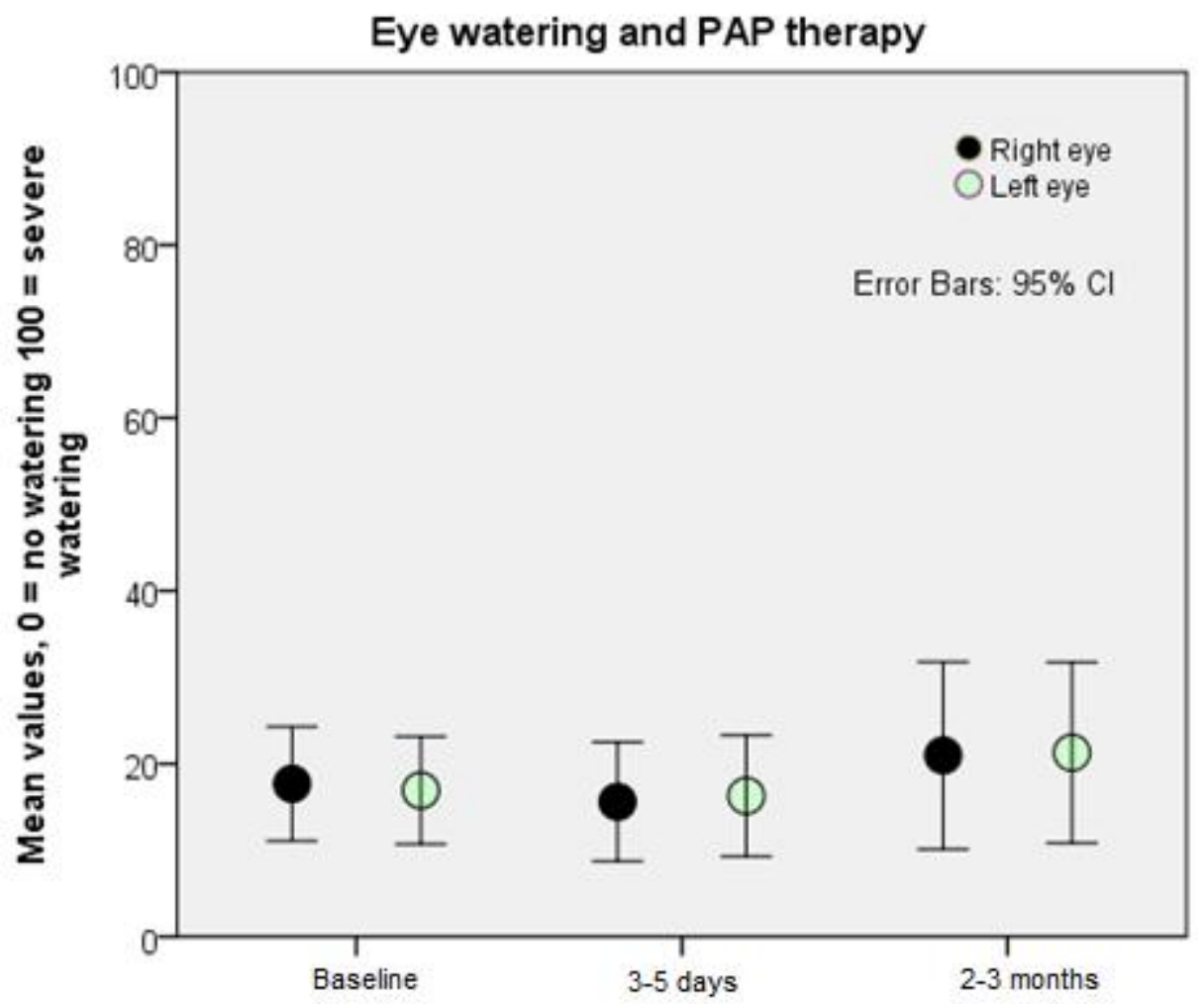

Figure 2: Watering values, at baseline and with PAP therapy (at four days and two months). No significant difference was found. 


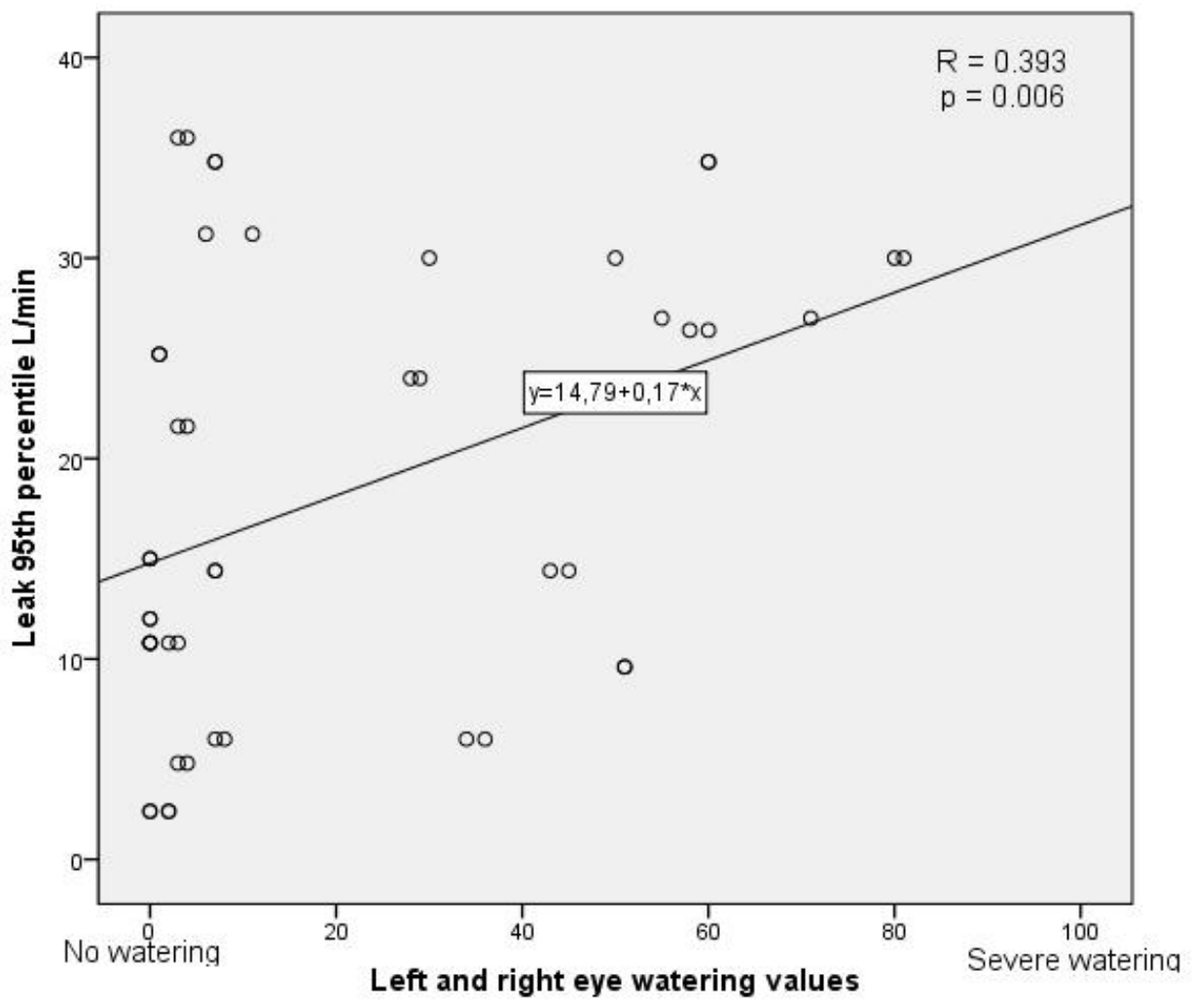

Figure 3: Bivariate Pearson correlation between left and right eye watering values and PAP $95^{\text {th }}$ air-leak values at two months of PAP therapy. 